\title{
Esporotricosis del pabellón auricular. Comunicación de un caso atípico simulando una celulitis bacteriana
}

\author{
Juan Ochoa-Reyes, Ernesto Ramos-Martínez, Rogelio Treviño-Rangel, Gloria M. González y Alexandro Bonifaz
}

\section{Auricular sporotrichosis. Atypical case report simulating bacterial cellulitis}

Sporotrichosis is the most common subcutaneous or implantation mycosis in Mexico. The case of a preauricular cutaneous-fixed sporotrichosis simulating atypical bacterial cellulitis is reported in an elderly patient with no history of trauma. The biopsy showed a suppurative granuloma with scarce yeast. Sporothrix schenckii was identified in the culture and confirmed by molecular biology. She was treated with itraconazole and a clinical and mycological cure was obtained. The case of atypical presentation is presented, coming from a semi-arid zone with extreme weather.

Key words: Sporotrichosis; Sporothrix schenckii; fixed-cutaneous; bacterial cellulitis; itraconazole; PCR Palabras clave: Esporotricosis; Sporothrix schenckii; cutánea-fija, celulitis bacteriana; itraconazol, RPC.

\section{Introducción}

$\mathrm{L}$ a esporotricosis es una micosis generalmente subcutánea, de curso subagudo o crónico. Es causada por hongos dimorfos comprendidos dentro del complejo Sporothrix schenckii, del cual se han identificado seis especies, siendo las tres más frecuentes y patógenas: S. schenckii (sensu stricto), Sporothrix brasiliensis, y Sporothrix globosa; y ocasionales: Sporothrix mexicana, Sporothrix lurei y Sporothrix pallida ${ }^{1-3}$. Es la micosis por implantación más ampliamente distribuida en el mundo y se observa con mayor frecuencia tanto en regiones intertropicales como en climas templados ${ }^{1,4,5}$.

Las diversas especies del complejo Sporothrix viven en el suelo, materia orgánica, plantas, paja, ramas, zacate y musgos. La infección se adquiere por inoculación traumática con material contaminado y puede transmitirse como una zoonosis por animales domésticos como perros y en especial, gatos. Se consideran grupos de riesgo de presentar la enfermedad: habitantes del medio rural, horticultores, trabajadores forestales, floristas y carpinteros. Por este motivo, la esporotricosis se le ha llamado la "enfermedad de los jardineros" o la "enfermedad de los cultivadores de rosas" $", 2,4,5$.

Comunicamos un caso de presentación atípica procedente de Chihuahua, México, una zona con clima semidesértico.

\section{Caso clínico}

Mujer de 84 años de edad, originaria y residente de la ciudad de Chihuahua, México, quien consultó por lesiones cutáneas en el pabellón auricular derecho, extendidas hasta la región preauricular. Al examen físico presentaba un eritema difuso, con edema de piel y tejidos blandos y lesiones vesículo-pustulosas con exudado purulento y costras melicéricas. En las áreas circunscritas se observaron úlceras con exposición del cartílago auricular (Figura 1A). La paciente se encontraba en buen estado general, sin fiebre, con discreto dolor y prurito local, sin adenopatías asociadas palpables. Las lesiones habían aparecido 12 días antes de la consulta, sin causa aparente y con una rápida progresión. La paciente negó el antecedente de algún traumatismo local, exposición a plantas espinosas o viajes fuera de la ciudad. No tenía historia de diabetes mellitus, uso de fármacos inmunosupresores u otro factor de riesgo. El diagnóstico clínico presuntivo fue de una celulitis bacteriana atípica indicándose tratamiento con ciprofloxacina $500 \mathrm{mg}$, dos veces al día, por 7 días, sin respuesta clínica. Por este motivo se realizó una biopsia de piel, cuyo estudio histológico demostró una inflamación crónica granulomatosa con presencia de linfocitos, células epitelioides, áreas focales de necrosis caseosa y numerosas células gigantes tipo Langhans. La tinción de Ziehl Neelsen fue negativa y la tinción de PAS reveló la presencia de escasas levaduras dentro de los granulomas, algunas de ellas en gemación, de 7 a $12 \mu \mathrm{m}$ de diámetro (Figuras 2 y 3 ).

Se realizó una radiografía de tórax y exámenes de laboratorio general (hemograma, perfil bioquímico y pruebas de función hepática) que fueron normales. Se tomó un cultivo corriente y micológico del exudado purulento. El cultivo corriente para bacterias resultó negativo. El cultivo micológico, sembrado en agar dextrosa Sabouraud y estudiado en el Laboratorio de Micología del Hospital General de México, desarrolló a los cinco días una colonia café claro, con pigmento oscuro, glabra y de superficie
Chihuahua, Chih, México. Especialidad en Dermatología (JOR).

Especialidad en Patología (ERM). Universidad Autónoma de Nuevo León, México.

Departamento de Microbiología, Escuela de Medicina (RTR, GMG) Hospital General de México

Dr. Eduardo Liceaga, Ciudad de México.

Departamento de Micología, Servicio de Dermatología (AB).

Sin financiamiento.

Sin conflicto de interés.

Recibido: 23 de julio de 2017 Aceptado: 28 de diciembre de 2017

Correspondencia a: Alexandro Bonifaz a_bonifaz@yahoo.com.mx 


\section{Caso Clínico}

Figura 1. A: Placa eritematocostrosa ulcerada y con edema de tejidos blandos, con áreas ulceradas, cartílago expuesto y exudado purulento. B: Pabellón auricular con regresión completa de las lesiones, tres meses después del inicio de itraconazol.
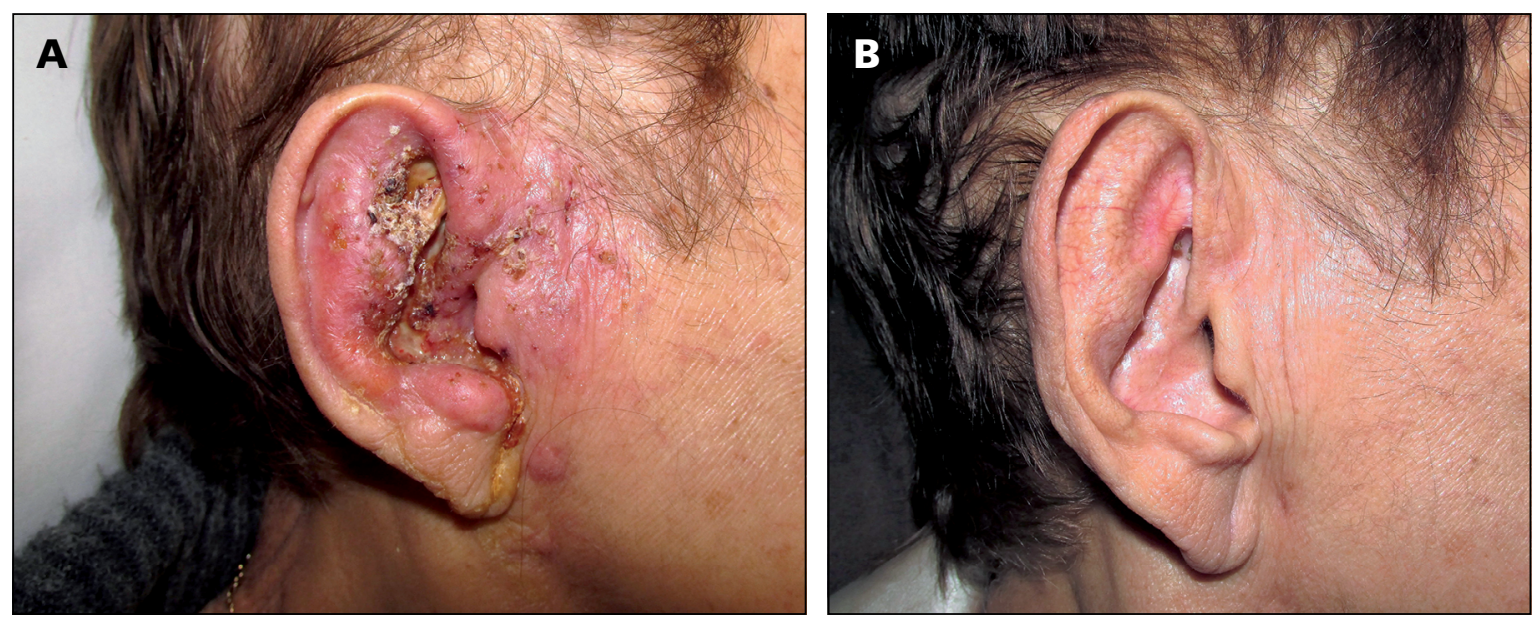

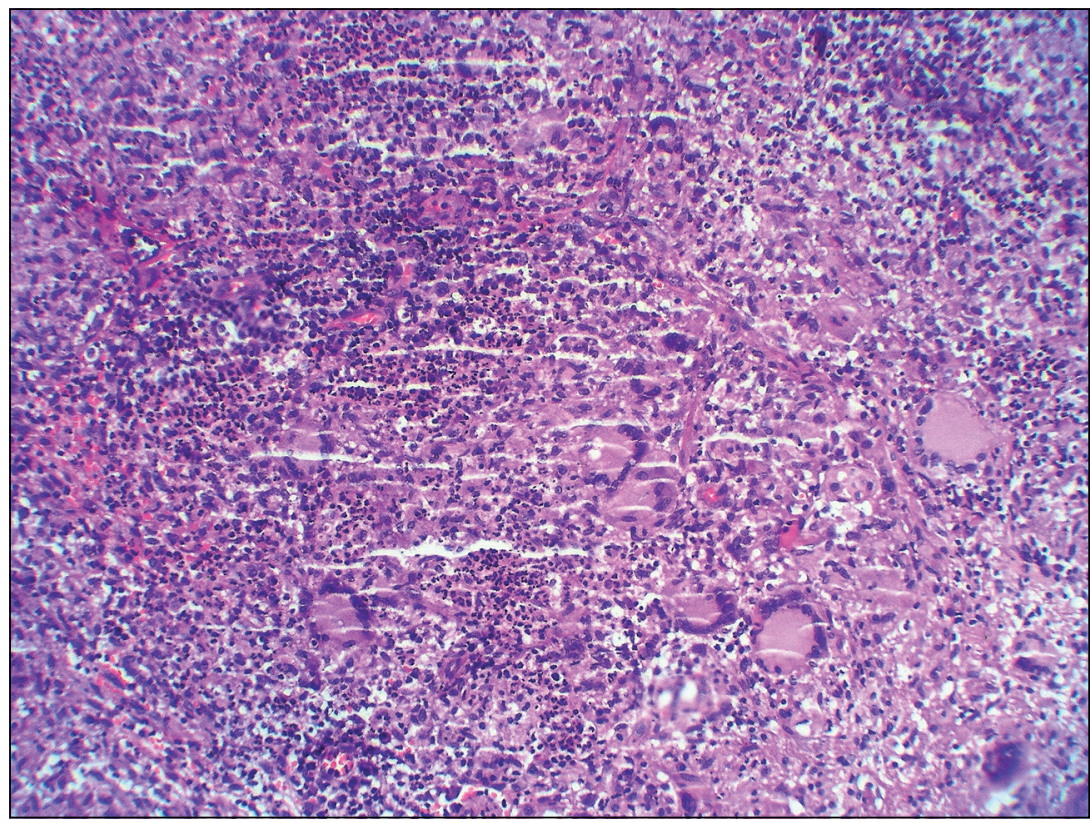

Figura 2. Inflamación granulomatosa con infiltrado linfocitario, células epitelioides, focos de necrosis caseosa y células gigantes tipo Langhans. ( $\mathrm{H}$ y E, 10X).

filamentosa, sin pigmentos al reverso. A la microscopia mediante microcultivos con eritrosina ( $2 \%$ ), se observaron múltiples filamentos delgados, con disposición en coremium y con reproducción por conidiación simpodial, que nacían de conidióforos cortos y otros sésiles directamente de las hifas. Se identificó por morfología como Sporothrix schenckii (sensu lato) (Figura 4). Para el estudio molecular de la cepa se realizó la extracción del ADN mediante el método de fenol cloroformo. Con el material genético obtenido se emplearon como templado para la amplificación del gen de calmodulina, los iniciadores

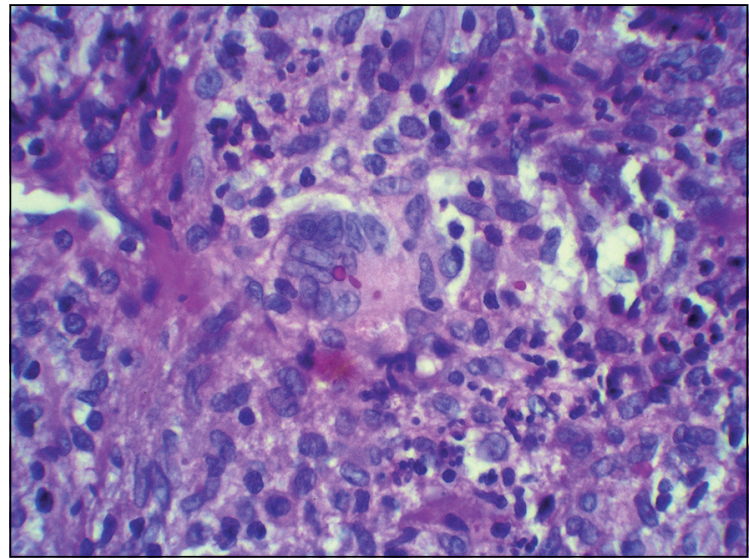

Figura 3. Tinción de PAS. Escasas levaduras, algunas con gemación, dentro de los granulomas (40X)

CL1 y CL2A, según lo descrito por O'Donnell ${ }^{6}$. Una vez verificados los amplicones mediante electroforesis en gel de agarosa al $0,5 \%$, los productos obtenidos se purificaron utilizando una prueba comercial (Wizard, Promega ${ }^{\circledR}$ ) y se secuenciaron. Finalmente, se llevó a cabo el análisis de secuencias mediante la plataforma BLAST del NCBI (https://blast.ncbi.nlm.nih.gov/Blast.cgi), identificando Sporothrix schenckii (sensu stricto).

El diagnóstico fue de una esporotricosis cutánea- fija, por lo que se inició manejo con itraconazol $200 \mathrm{mg}$ al día, con buena respuesta clínica. Sin embargo, en la primera semana del tratamiento se encontró un nódulo preauricular y otro subcutáneo, indoloro, en la cara interna del brazo derecho, que regresó después de varias semanas. La terapia se prolongó por tres meses con recuperación completa, sin evidencia de recaída a los nueve meses post-tratamiento (Figura 1B). 


\section{Discusión}

La esporotricosis es un entidad clínica polimorfa. Dentro de sus formas, sólo la cutánea-linfangítica es característica y casi distintiva; sin embargo, las formas cutánea-fija y cutánea-diseminada pueden representar un verdadero reto diagnóstico. En México, la forma fija se observa en $20-30 \%$ de los casos y existen países donde suele ser la forma predominante, como en Japón, Corea o Costa Rica. Se presenta como una placa eritematosa infiltrada, verrucosa o con componente nodular, que puede ulcerarse y cubrirse con costras melicéricas ${ }^{1,5,7-9 \text {. }}$ Sin embargo, se describen formas atípicas con aspecto de sarcoidosis, rosácea, carcinoma basocelular, carcinoma epidermoide, queratoacantoma, sarcoma y pioderma gangrenoso $\mathrm{O}^{2,4,10}$.

El diagnóstico debe confirmarse a través del cultivo ${ }^{1,2,4}$. En México, aunque se cita que la enfermedad existe en la mayoría de los estados del país, en muchas regiones está sub-diagnosticada y sub-reportada, en parte porque no se cuenta con acceso fácil a laboratorios especializados.

La zona de mayor endemia en México se localiza en el occidente, sobre todo en Jalisco y Nayarit, seguida del centro del país. La Sierra Norte de Puebla se considera una región hiperendémica de esporotricosis ${ }^{1,2,7}$; incluso en algunas regiones como la comunidad de Xilocuautla, $53 \%$ de los habitantes estudiados resultó con positividad a la intradermorreacción con esporotricina. Con una prevalencia de 25 casos por cada 1.000 habitantes, es una de las zonas de mayor contacto con el hongo y varios casos publicados de la enfermedad ${ }^{8}$.

El aspecto morfológico de la lesión de nuestra paciente, con marcada reacción inflamatoria, descarga purulenta y rápido avance, nos hizo pensar en una infección bacteriana atípica de tejidos blandos, debido a que no manifestaba el característico dolor e hipertermia local de los procesos piógenos. Así mismo, se pudo descartar una sobreinfección bacteriana secundaria a la esporotricosis, debido a que el cultivo para bacterias no mostró desarrollo y no hubo respuesta al tratamiento antibacteriano. Probablemente, la edad avanzada de la paciente fue un factor que condicionó el rápido y agresivo desarrollo de la lesión.

La esporotricosis cutánea-fija en el pabellón auricular es poco frecuente. Se presenta generalmente en individuos que cargan diversos materiales sobre los hombros por inoculación directa. Esta localización debe distinguirse de la leishmaniasis (úlcera del chiclero), en pacientes que habitan o hayan viajado a regiones tropicales ${ }^{1,11}$. En nuestra paciente, el diagnóstico diferencial más importante fue la coccidioidomicosis, debido a que vivía en una zona endémica (norte de México) y además porque esta micosis también presenta un patrón histológico granulomatoso. La esporotricosis está presente en el Estado de Chihuahua, donde existen casos causados por contaminación de zacate

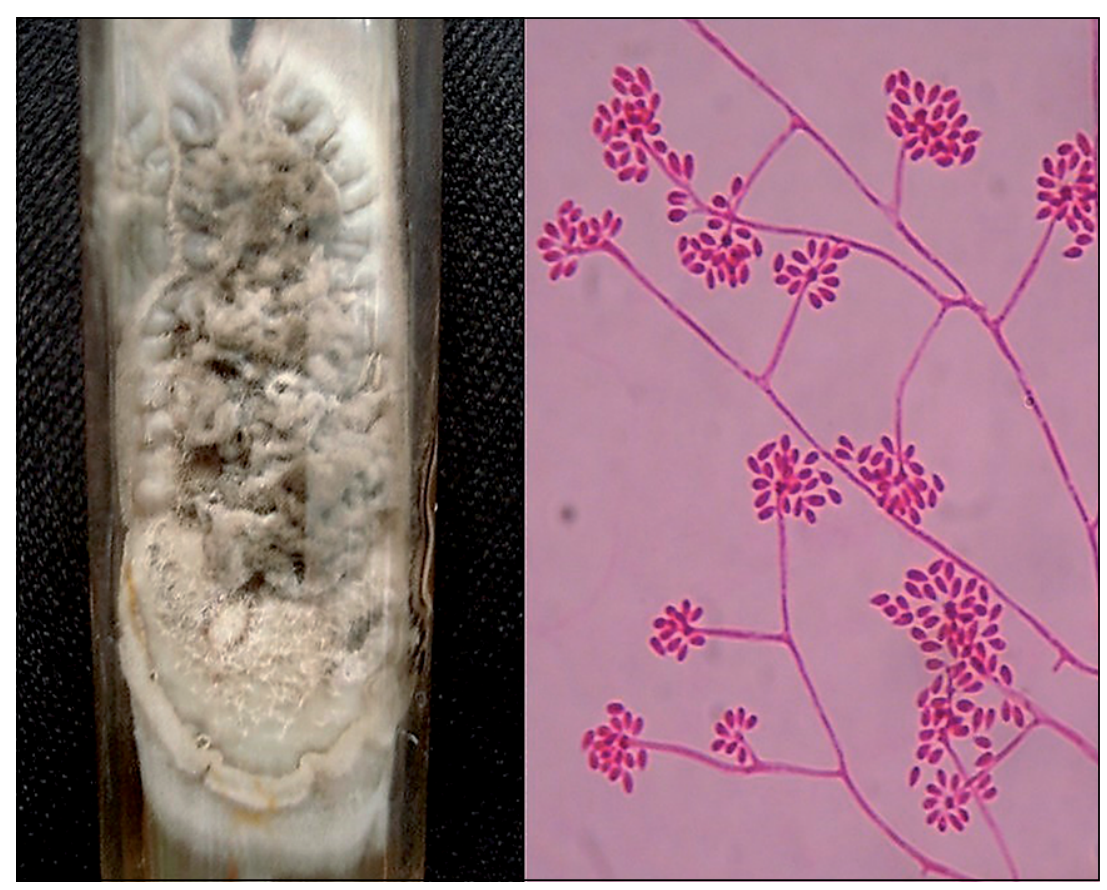

Figura 4. Cultivo de Sporothrix schenckii en medio Sabouraud y microscopia de conidiación simpodial en forma de "pétalos de margarita" (eritrosina 2\%, 40X).

para envolver loza, por lo que no se considera que el hongo se haya desarrollado en la zona desértica ${ }^{12}$.

En Latinoamérica la esporotricosis ha sido reportada en diversos países. Entre 1998 y 2009, en Río de Janeiro se comunicó un brote epidémico por transmisión zoonótica desde gatos enfermos, con más de 2.200 personas y 3.200 gatos afectados ${ }^{1,9}$. También se ha descrito una hiperendemia en la zona andina del Perú (Abancay) ${ }^{13}$ y diversos casos en Argentina, Uruguay, Colombia, entre otros ${ }^{5}$. En Chile se han comunicado casos autóctonos cutáneolinfáticos, uno causado por $S$. schenckii (ss) y otro por $S$. globosa, en la región de Valdivia ${ }^{14,15}$, en zonas boscosas húmedas y frescas, lo que dista mucho de nuestro caso proveniente de una región semidesértica, con promedios altos de temperatura y poca precipitación pluvial.

El cultivo es el estándar de oro para establecer el diagnóstico. Se utiliza por lo regular agar dextrosa Sabouraud, con o sin antimicrobianos. Las colonias se desarrollan en cinco a ocho días a $28^{\circ} \mathrm{C}$, adoptando un aspecto membranoso. Al examen microscópico se observa una conidiación simpodial en forma de "pétalos de margarita" o "flores de durazno". El examen directo $(\mathrm{KOH})$ y las tinciones como el PAS y el Grocott del exudado de las lesiones, raras veces son útiles, ya que las levaduras son muy escasas, o bien son difíciles de distinguir ${ }^{1,2,4}$. La excepción la constituyen los casos anérgicos en pacientes inmunocomprometidos o bien en muestras de gatos, 
donde suelen observarse abundantes levaduras de formas elongadas ${ }^{1,2,16}$.

La histopatología puede orientar, pero no es patognomónica. En general, se observa una reacción inflamatoria con un componente mixto, granulomatoso y supurativo, que puede confundirse con la tuberculosis, otras micosis profundas y con sífilis ${ }^{2,4}$. Con tinciones de PAS y Grocott ocasionalmente llegan a detectarse blastoconidios o células en gemación muy aisladas. En nuestra experiencia lo observamos en menos de $5 \%^{2}$ de los casos, aunque Quintella y cols. ${ }^{17}$ describen hasta 35\% de identificación de levaduras y cuerpos asteroides; estos últimos representan la expresión del fenómeno de Splendore-Hoeppli²,17. La intradermorreacción con esporotricina es muy útil para el diagnóstico, con una sensibilidad de más de $90 \%$. Sin embargo, en zonas endémicas una reacción positiva puede reflejar una primoinfección o una enfermedad previa ya resuelta. No es una técnica estandarizada y por ende, no aceptada por muchos países ${ }^{1,2,4,8}$. A través de la RPC puede lograrse la identificación molecular de $S$. schenckii, con una sensibilidad y especificidad de 95\%; sin embargo, la prueba no está fácilmente disponible en nuestro medio ${ }^{1,4}$.

Nuestra paciente no tenía al parecer factores de riesgo para adquirir la enfermedad. Por su edad avanzada y una prótesis de rodilla fallida, sus desplazamientos eran muy limitados dentro del hogar. Sin embargo, en una visita domiciliaria pudimos constatar una convivencia estrecha con su perro (de apariencia sana). Sospechamos que el hongo pudo haberse inoculado a través de un rasguño inadvertido. Se ha descrito que la esporotricosis puede adquirirse por animales que actúan como vectores indirectos o pasivos al transportar el agente en garras, uñas o dientes. Se han implicado mayormente a ratas, ratones, ardillas y armadillos ${ }^{2,4}$. En contraste, en la epidemia de esporotricosis de transmisión zoonótica en Brasil ( $S$. brasiliensis), la infección fue transmitida por gatos, los que cursan con una infección diseminada con lesiones extensas con levaduras abundantes ${ }^{1,9,18}$.

Tradicionalmente, el tratamiento de primera elección ha sido el yoduro de potasio, el que es el más utilizado en países subdesarrollados por ser efectivo, bien tolerado y de bajo costo; sin embargo, con algunos efectos colaterales $^{1,4,19}$. Su uso se reserva a la forma cutánea-fija y linfangítica. Sin embargo, según las guías terapéuticas de la esporotricosis, el tratamiento de elección para las formas cutáneas linfangítica y fija es itraconazol, a dosis continua de 100 a $200 \mathrm{mg}$ al día, por períodos de tres a cuatro meses (se le ha utilizado también en pulsos). Su efectividad es superior a $90 \%$. En pacientes inmunocomprometidos o casos con enfermedad diseminada la dosis debe elevarse a 300-400 mg al día ${ }^{2,19-22}$. Terbinafina parece ser menos efectiva en la práctica que itraconazol (aunque in vitro presenta CIM más bajas) ${ }^{19}$, sin embargo, en un estudio comparativo se encontró que $250 \mathrm{mg}$ al día de terbinafina fue igualmente efectivo que $100 \mathrm{mg}$ al día de itraconazol ${ }^{22}$. Es una buena alternativa al itraconazol en caso de intolerancia o por múltiples interacciones farmacológicas ${ }^{19}$.

\section{Resumen}

La esporotricosis es la micosis subcutánea o por implantación más frecuente en México. Se comunica el caso de una esporotricosis cutánea-fija preauricular que simuló una celulitis bacteriana atípica, en una paciente anciana sin antecedente de traumatismo. La biopsia mostró un granuloma supurativo con presencia de levaduras escasas. En el cultivo se identificó Sporothrix schenckii que se confirmó por biología molecular. Se trató con itraconazol obteniéndose una curación clínica y micológica. Se presenta el caso de presentación atípica, proveniente de una zona semidesértica con clima extremo.

\section{Referencias bibliográficas}

1. Barros M B, de Almeida Paes R, Schubach A O. Sporothrix schenckii and sporotrichosis. Clin Microbiol Rev 2011; 24: 633-54.

2. Bonifaz A, Vázquez-González D. Sporotrichosis: an update. G Ital Dermatol Venereol 2010; 145: 659-73

3. Marimon R, Cano, J Gene J, Sutton D A, Kawasaki M, Guarro J. Sporothrix brasiliensis, S. globosa, and S. mexicana, three new Sporothrix species of clinical interest. J Clin Microbiol 2007; 45: 3198-206.

4. Arenas R. Sporotrichosis. En: Topley \& Wilsongs, Merz WG \& Hay R, eds. Microbiology and Microbial Infections, 10th ed. Hodder-Arnold, London, UK, 2005: pág 367-84.

5. Chakrabarti A, Bonifaz A, Gutiérrez-Galhardo MC, Mochizuki T, Li S. Global epidemiology of sporotrichosis. Med Mycol 2015; 53: 3-14.

6. O’Donnell K, Nirenberg H I, Aoki T, Cigelnik E. A multigene phylogeny of the Gibberella fujikuroi species complex: Detection of additional phylogenetically distinct species. Mycoscience 2000; 41: 61-78.

7. Macotela-Ruiz E, Nochebuena-Ramos E. Esporotricosis en algunas comunidades rurales de la Sierra Norte de Puebla. Informe de 55 casos. Gac Méd Méx 2006; 142: 377-80.

8. Bonifaz A, Araiza J, Pérez-Mejía A, Ochoa LA, Toriello C. Prueba intradérmica con esporotricina en una comunidad de la Sierra Norte de Puebla. Dermatol Rev Mex 2013; 57:428-32.

9. Barros M B, Schubach T P, Coll, J O, Gremião I D, Wanke B, Schubach A. Sporotrichosis: development and challenges of an epidemic. Rev Panam Salud Publica 2010; 27: 455-60.

10. Mosena G, Schwarzbach A P, Bonkevitch F, Musa F, Silveira dos Santos I, Lamonatto $\mathrm{S}$, et al. Fixed sporotrichosis mimicking keratoacanthoma. J Am Acad Dermatol 2016; 74 Suppl 1: AB158.

11. Arenas-Soto C M, Téllez-Kling A M, AlvaradoÁlvarez Z L. Lesión infecciosa del pabellón auricular en el trópico. Actas Dermosifilogr 2016; 107: 599-600. 
12. Carrada-Bravo T. Esporotricosis: Avances recientes en el diagnóstico de laboratorio, histopatología y la epidemiología en México. Rev Latinoamer Patol Clin 2012; 59:147-71

13. Ramírez Soto M C, Malaga G. Subcutaneous mycoses in Peru: a systematic review and meta-analysis for the burden of disease. Int J Dermatol 2017; 56:1037-45.

14. Oddó D, Lobos T. Micosis inusuales en Chile. Reporte de 10 casos. Rev Med Chil 1988; 116 1135-42

15. Cruz R, Vieille P, Oschilewski D. Aislamiento ambiental de Sporothrix globosa en relación a un caso de esporotricosis linfo-cutánea. Rev Chilena Infectol 2012; 29: 401-5

16. Rudramurthy S M, Chakrabarti A. Sporotrichosis: Update on diagnostic techniques. Curr Fungal Infect Rep 2017; 11:134-40

17. Quintella L P, Passos S R, do Vale A C, Galhardo M C, Barros M B, Cuzzi T, et al. Histopathology of cutaneous sporotrichosis in Rio de Janeiro: a series of 119 consecutive cases. J Cutan Pathol 2011; 38: 25-32.

18. Barros M B, Schubach Ade O, do Valle A C, Gutierrez Galhardo M C, Conceição-Silva F, Schubach T M, et al. Cat-transmitted sporotrichosis epidemic in Rio de Janeiro, Brazil: description of a series of cases. Clin Infect Dis 2004; 38: 529-35.

19. Bonifaz A, Vázquez-González D. Diagnosis and treatment of lymphocutaneous sporotrichosis: what are the options? Curr Fungal Infect Rep 2013; 7: 252-9.
20. de Lima Barros M B, Schubach A O, de Vasconcellos Carvalhaes de Oliveira R, Martins E B, Teixeira J L, Wanke B. Treatment of cutaneous sporotrichosis with itraconazolestudy of 645 patients. Clin Infect Dis 2011; 52: e200-6.

21. Bonifaz A, Fierro L, Saul A, Ponce R M. Cutaneous sporotrichosis. Intermittent treatment (pulses) with itraconazole. Eur J Dermatol 2008; 18: 61-4.

22. Francesconi G, Francesconi do Valle A C, Passos S L, de Lima Barros M B, de Almeida Paes R, Curi A L, et al. Comparative study of $250 \mathrm{mg} /$ day terbinafine and $100 \mathrm{mg} /$ day itraconazole for the treatment of cutaneous sporotrichosis. Mycopathologia 2011;171: 34954. 